\title{
Community-Based Health Insurance Enrollment and Determinants in Addis Ababa: Insights from Behavioral Economics and Discrete Choice Experiments
}

\author{
Abel Eshetu 1, *, Abrham Seyoum ${ }^{2}$ \\ ${ }^{1}$ Zemen Bank Risk Management Department, Addis Ababa, Ethiopia \\ ${ }^{2}$ Center for Rural Development, College of Development Studies, Addis Ababa University, Addis Ababa, Ethiopia \\ Email address: \\ ehiaabel2013@gmail.com (A. Eshetu), abrhams3@gmail.com (A. Seyoum) \\ ${ }^{*}$ Corresponding author
}

To cite this article:

Abel Eshetu, Abrham Seyoum. Community-Based Health Insurance Enrollment and Determinants in Addis Ababa: Insights from Behavioral Economics and Discrete Choice Experiments. International Journal of Health Economics and Policy. Vol. 4, No. 4, 2019 , pp. $158-167$. doi: $10.11648 /$ j.hep. 20190404.16

Received: July 13, 2019; Accepted: August 7, 2019; Published: December 26, 2019

\begin{abstract}
Community-based health insurance target those employed in the rural and informal sector in urban by pooling risks and protect households from out-of-pocket expenditures when receiving health facility services. However, Ethiopian community-based health insurance is schemes characterized by low enrollment. The aim of this study is to analyze the determinants of community-based health insurance enrollment in Addis Ababa from behavioral economics and discrete choice experiment insights. A total of 222 households from ten pilot woredas were selected for the study using a simple random sampling technique. A simple social experiment is used to examine the significance of behavioral biases. A discrete choice experiment conducted across three attributes and conditional logit model used to determine the relative importance of the selected attributes and willingness-to-pay for those attributes. In addition, the binary logit regression model is used to estimate the probability of households enrollment in community-based health insurance. The study result indicates that households have the highest willingness to pay for only private health service providers (Birr 1849.6/year) compared to status-quo level. Nonmember households' willingness to pay for comprehensive health service package Birr 2271.7/year. Moreover, this study revealed loss-aversion bias, over-optimistic bias, and herding bias had significantly affected the household decision on community-based health insurance enrollment. The study suggests that behavioral biases affect Community-based health insurance enrollment. The study finding also reveals that respondent households are willingness to pay more for comprehensive health service package and for health insurance scheme that includes private health service providers. In addition, the study concludes eligible household enrollment decision varied based on their socio-demographic and household characteristic. This study recommends the need to consider mandatory community-based health insurance schemes and apply targeting intervention (coverage) to the particular group.
\end{abstract}

Keywords: Community Based Health Insurance, Behavioral Biases, Discrete Choice Experiment, Willingness to Pay, Addis Ababa

\section{Introduction}

In Ethiopia, based on the 6th edition of national health accounts, about $33 \%$ of the total health care expenditure is attributed to the out of pocket payment by the households it is the largest proportion of health spending [19]. Ethiopia's per capita spending on health reached $\$ 28.65$ in $2013 / 14$ however this is still far below the globally recommended $\$ 60$ per capita estimated to make essential health care services available in low-income countries [20]. To expand financial protection to reduce the financial burden that health spending imposes on households and to upsurge health service utilization, the Ethiopian government implements demandside initiatives called Community-Based Health Insurance (CBHI). CBHI target those employed in the rural and informal sector in urban by pooling risks and protect 
households from out-of-pocket expenditures when receiving health facility services. Large risk pools offer better financial risk protection, enhance income, and risk cross-subsidization.

Health sector transformation plan 2015/16 - 2019/20 [19] sets a target to establish community-based health insurance (CBHI) schemes in $80 \%$ of woredas and enroll at least $80 \%$ of households, and plan to collect 375.6 million USD from members. However, Ethiopian CBHI schemes characterized by low enrollment. It is similar in many Sub-Saharan Africa countries enrolment not often reaches more than $10 \%$ of the eligible population with some exceptions in countries such as Rwanda and Ghana [9].

Multiple studies carried out to know which factor determines and affect $\mathrm{CBHI}$ enrolment [4, 6, 11, 18]. All those studies based on neoclassical model peoples make decisions rationally generally assumes that people have full information and know what is best for themselves built upon utility maximization and expected utility theory. However, all peoples decision-making not only affected or determined by neoclassical assumptions but also the decision-making process with people affected or determined by psychological character. Behavioral economics has shown that the human mind poses pitfalls that drive humans away from rationality. Baicker and his colleagues describe uninsured individuals not enrolled in very low-cost health insurance scheme using behavioral economics approaching from psychology into the economic analysis [7].

In addition, those previous studies did not examine willingness to pay for the current $\mathrm{CBHI}$ schemes by providing different alternative using a discrete choice experiment (DCE). In this time accepted eliciting stated preference model in health economics is discrete choice experiments (DCE). Discrete choice experiments (DCEs) involve a process of developing, testing and optimizing the experiment questionnaire [9, 14-16]. DCEs need respondents select their choice over sets of supposed options which each alternative explained by a set of attributes, and all attribute catches one of a number of levels [9, 14-16].

Ethiopian Community-based health insurance (CBHI) schemes face challenges in establishing and sustaining $\mathrm{CBHI}$ schemes. Community-based health insurance (CBHI) schemes characterized are low rates of individuals' member enrollment leading to low CBHI coverage. This study explains the reason low take-up of CBHI in Addis Ababa from behavioral economics insight. In addition, this study explains the individual preference of different $\mathrm{CBHI}$ attributes and willingness to pay each attribute of the $\mathrm{CBHI}$ by applying discrete choice experiments (DCE) model.

\section{Method}

\subsection{Design for Simple Social Experiment}

To examine the relationship between behavioral biases and CBHI enrollment, this study applied quantitative simple social experiment. Households who are enrolled and unenrolled in community based health insurance schemes are included in the survey. The survey contains four hypothetical choice questions related to loss-aversion bias, status quo bias, over-optimistic bias, and herding bias.

\subsubsection{Loss Aversion Bias}

Keep away from the pain of losing by taking more risk. To assess and test loss aversion bias, two scenarios that have two alternatives each were given and the respondents were asked to respond by choosing alternatives in each of them. In scenario one, the respondent asked to choose between alternative an (An assured gain of Birr 350) and alternative $b$ (After a coin toss if it is King you get Birr 700 but if it is Lion you get noting). In scenario two the respondent asked to choose between alternative c (An assured loss of Birr 350) and alternative $d$ (After a coin toss if it is King you get Birr 700 but if it is Lion you get noting). Loss averse household choice alternative a. in scenario one, preferring the assurance of profit to the outcome, even though (in the long run) the outcome will yield a higher payoff. On the other hand, rather than subject themselves to a certain loss of, loss-averse household select the alternative $\mathrm{d}$ in scenario two, even though they will lose more money in the long run.

\subsubsection{Status Quo Bias}

In many different reasons, households might prefer the current situation than join CBHI schemes. To asses and test status quo bias two scenarios that have two alternatives each were given and the respondents were asked to respond by choosing alternatives in each of them. In scenario one the respondent asked, would you buy a lottery ticket with a $1 \%$ chance of winning one hundred thousand birr (sold at 1,000 Birr) ? In addition, households were asked to choose between alternative a (No, I would not buy a lottery ticket) and alternative $\mathrm{b}$ (Yes, I would buy a lottery ticket).

In scenario two the respondent was asked, suppose you already own a lottery ticket with a $1 \%$ chance of winning hundred thousand birr. As the winning lottery, a ticket will be announced one year later, you will receive one hundred thousand birr one year later even if you own a winning lottery ticket. Are you willing to sell the lottery ticket if somebody asks you to sell it now at 1,000 Birr? In addition, households were asked to choose between alternative c (No, I am not willing to sell a lottery ticket) and alternative d (Yes, I am willing to sell a lottery ticket). The respondent household who has status quo behavior select alternative a form scenario one and alternative $\mathrm{c}$ from scenario two.

\subsubsection{Over-Optimistic Bias}

Households might believe they have a low chance get any illness than their peers and they may decide not to join the schemes. To asses and test over-optimistic bias the respondents were asked the following question- How likely do you think you are to getting serious illness and go to the hospital for treatment at some point in the future? This variable was measured on a four-point Likert scale (one= Very unlikely; 4= Very likely). Afterward, the data were regrouped into two categories as "likely and unlikely" for numerical significance and to simplify the analyses and data 
interpretation.

\subsubsection{Herding Bias}

Householdsmight be following the CBHI enrollment decision of other households. To asses and test herding bias, the respondents who have $\mathrm{CBHI}$ awareness were asked the following question: My neighbors and friends were important sources of information when I decide to join/Not to join community-based health insurance scheme. However, for respondents who do not have CBHI awareness were asked in the following form: In the future when I decide to join or not to join community-based health insurance scheme my neighbors and friends will be an important source of information. This variable was measured on a four-point Likert scale (one=Strongly Agree; 4=Strongly disagree). Afterward, the data were regrouped into two categories as "Agree and disagree" for numerical significance and to simplify the analyses and data interpretation.

\subsection{Discrete Choice Experiment}

\subsubsection{Identification of Attributes and Assignment of Levels}

Two focus group discussions with five households in each group conducted using a local language Amharic in Lideta Sub City (Woreda/District 01) and Yeka Sub City (Woreda/District 02) with households who do not have a community health insurance and with those who have a community health insurance. In addition, five key informant interviews were conducted in the Ethiopian Health Insurance Agency (Two experts from Members Contribution Directorate, two experts from Health service providers Directorate and one expert from research and planning Directorate).

After exhaustive consultations of related literature, policy documents and government reports reviews, FGDs, and key informant interviews, an initial discrete choice experiment (DCE) design was set up with three CBHI attributes and their associated levels (Table 1).

Table 1. Attribute and Levels of Addis Ababa CBHI Schemes.

\begin{tabular}{lll}
\hline Attributes & Levels & Description \\
\hline $\begin{array}{l}\text { Premium } \\
\text { Health Service providers }\end{array}$ & $\begin{array}{l}350 \text { Birr, 500 Birr, 800 Birr and 1500 } \\
\text { birr }\end{array}$ & Yearly contribution to join in the schemes \\
$\begin{array}{l}\text { PSP) } \\
\text { Benefit package (BP) }\end{array}$ & $\begin{array}{l}\text {-No Exclusion from the package and }- \\
\text { Exclusion of dialysis from the package }\end{array}$ & $\begin{array}{l}\text { Private- Health facilities held by private investors } \\
\text {-Health insurance package related to exclusion and } \\
\text { inclusion of health services }\end{array}$ \\
\hline
\end{tabular}

(i) Premium: The annual premium a member will pay for the scheme. In FGD, many of them want low amount premiums of 350 birr and 500 Birr. However, based on information from the Ethiopian Health Insurance Agency strategy document, additional premiums of 800 birr and 1500 birr were added.

(ii) Health Service providers: These attributes represent the types of health facilities, which provide health service for community health insurance scheme members. This attribute has three levels: Public health service provider, private health service provider and public and private health service provider.

(iii) Benefits Package: Health insurance package related to exclusion and inclusion of health services. There are some health services excluded from CBHI like - dental, dialysis, etc... However, based on the information gathered from FGDs and key informant interviews, dialysis is found to be the main concern for households. Therefore, this attribute has two levels of comprehensive health service packageand the Exclusion of dialysis from the package.

\subsubsection{Experimental Design}

In this study, a fractional factorial design applied used to select a reduced sample of choices. The most efficient design known as D-efficiency is applied by using a statistical software package. Using STATA 14.2 software package of dcreatecommand, paired choice alternatives were reduced from 1,128 to 16 , and blockdes command was used to randomly divide the design into two blocks, which have eight choices set each. Therefore, each household faced eight choice sets. All choice sets had two alternatives (Alternative A and Alternative B) with status-quo. In this study neither of two options (status quo) represent and define as households who don't want to choose between two alternatives, also it was cleared to the respondent what does it mean (see Table 2).

Table 2. Example of Choice set.

\begin{tabular}{lll}
\hline & Alternative A & Alternative B \\
\hline Premium & 800 & 350 \\
Health Service providers & Public & Public \& Private \\
Benefit package & Exclusion of dialysis from the package & No Exclusion from the package \\
Which of the alternatives do you prefer?
\end{tabular}




\subsection{Design for Cross-sectional Survey}

To identify the main Socio-demographic and Household characteristics that affect CBHI enrollment in Addis Ababa, a cross-sectional household survey was carried out using a structured questionnaire.

\subsection{Sample Design}

The target population for this research was eligible households who live in ten piloted Woredas, which have already started Community Health Insurance. Both community-based health insurance members and nonmembers were targeted from those ten pilot Woredas. Accordingly, a simple random sample was drawn within each subgroup. The sample size determines to be 222 (by adding $10 \%$ of anticipated non-respondents).

\subsection{Data Analyses}

\subsubsection{Chi-square Test}

The Chi-square test was conducted to identify if there aresignificant differences between members and nonmembers' decision on community health insurance membership related to the behavioral biases mentioned above.

\subsubsection{Econometrics Approach DCE}

In this study, the analysis of DCE followed McFadden

$$
V_{\text {in }}\left(\mathrm{X}_{\text {in }} \beta\right)=\text { Con }+\beta_{1} \text { Premium }_{\text {in }}+\beta_{2} \text { Public }_{\text {in }}+\beta_{3} \text { Private }_{\text {in }}+\beta_{4} \text { Pub_n_Pri }_{\text {in }}+\beta_{5} \text { No_Exclui }_{\text {in }}+\beta_{6} \text { Exclu_dia }_{\text {in }}
$$

ConRepresent alternative-specific constant (ASC) captures the mean effect of the unobserved factors in the error terms for each of the alternatives. The coefficient of $\beta$ 's estimated as a conditional logit model and the model was estimated in STATA 14.2 applying the maximum likelihood approach using clogit command.

(i) Willingness to pay (WTP)

Let Premium $_{i}$ monetary value of continuous variable and $X_{i}$ non-monetary attribute, the monetary value for other attributes can be estimated. Therefore:

$$
W T P=-\frac{\partial U_{i} / X_{i}}{\partial U_{i} / \text { Premium }_{i}}=-\frac{\beta_{S}}{\beta_{1}}
$$

Where $\beta_{s}$ the coefficients of are non-monetary attributes and $\beta_{1}$ is the coefficient of monetary attribute premium. In
[17]. The hidden utility of CBHI alternative $i$ in a choice set $C_{n}$ perceived by household $n$ is decomposed into two parts. The CBHI attribute alternative $V_{i n}\left(\mathrm{X}_{i n} \beta\right)$ and unexplained factor that affects utility $\varepsilon_{i n}$. Therefore, the random utility $U_{i n}$ to individual $n$ associated with CBHI $i$ can defined as:

$$
U_{i n}=V_{i n}\left(\mathrm{X}_{i n} \beta\right)+\varepsilon_{\text {in }}
$$

Household $n$ chooses the CBHI alternative $i$ if and only if the utility of alternative $i$ is greater than CBHI alternative $j$ (ifonlyif $U_{i n}>U_{j n} \forall j \neq i$ ), where $j$ is included in choice set $C_{n}$. With random utilities $U_{n i}$ and a feasible choice set $i$, utility maximization implies choice probabilities [17]:

$$
\operatorname{Prob}\left(V_{i n}-V_{j n}>\varepsilon_{i n}-\varepsilon_{j n}\right) \forall i \neq j \in C_{n}
$$

This study used Conditional Logit model to analyze the DCE. A conditional logit model can assess the utility of each choice alternative for the individual characteristics and order to ensure minimal error in the estimation process $[2,12]$. A Hausman- McFadden test shows that the restrictive assumption IIA property is not violated.

In all the discrete choices, the deterministic part of the utility function $V_{i n}\left(\mathrm{X}_{\text {in }} \beta\right)$ assumed the linear-in-parameters function of the levels of the Community-based health insurance attributes as shown in equation 3 below. estimating the implicit prices, ceteris paribus assumption is held. This result can be used to evaluate the relative significance of all attributes by computing the degree to which each attribute is valued in terms of a cost attribute [2]. Calculation of WTP applied in STATA 14.2 using nlcom command.

\subsubsection{Econometrics Approach for Determinants of CBHI Enrollment}

The binary Logit regression model is used to identify CBHI scheme pilot Woredas of Addis Ababa and to determine which factors that affect $\mathrm{CBHI}$ enrollment.

Then, binary logistic regression defines as follows. factors affecting the probability of household's enrollment in

$$
\operatorname{logit}\left(Y_{i}\right)=\ln \left(\frac{p_{i}}{1-p_{i}}\right)=\beta_{0}+\beta_{1} X_{1 i}+\beta_{2} X_{2 i}+\cdots+\beta_{i} X_{n i}
$$

For the propose of this study binaryLogit regression is defined as follows:

$$
\begin{gathered}
\operatorname{logit}\left(C B H I_{i}\right)=\ln \left(\frac{p_{i}}{1-p_{i}}\right)=\beta_{0}+\beta_{1} \text { agegroups }_{i}+\beta_{2} \text { gender }_{i}+\beta_{3} \text { Mari_status }_{i}+\beta_{4} \text { Emp_status }_{i}+\beta_{5} \text { Edu_year }_{i}+ \\
\beta_{6}{\text { Visited } 6 m_{i}}_{i}+\beta_{7} \text { Awareness }_{i}+\beta_{8} \text { Dep_ratio }_{i}+\varepsilon_{i}
\end{gathered}
$$

The coefficient of $\beta$ 's can be estimated as a binary logit model, the model was estimated in STATA 14.2 using the maximum likelihood approach. Where, $p_{i}$ is the CBHI enrollment status of household $i$, a binary variable with a value of 1 if the household enrolled into CBHI and 0 if otherwise; agegroups $_{i}$ refer to which age group household fails; gender $_{i}$ refers sex of the household head; Mari_status $_{i}$ refers to the marital status of the household head; Emp_status ${ }_{i}$ refers to the employment status of the household head; $E d u_{-} y_{e} a r_{i}$ refers education level of the household head;Visited $6 m_{i}$ refers health 
center visited the last six months; Awareness $_{i}$ refer awareness on $\mathrm{CBHI}$ and Dep_ratio $i$ refer dependency ratio.

\section{Result}

\subsection{Description of the Study Participants}

From the total planed 222 sampled households, $220(99 \%$ response rate) interview questionnaires forwarded to the heads of the households or a responsible and representative in case their absence were complete. Accordingly, $110(50 \%)$ from community health insurance members and $110(50 \%)$ from non-members were interviewed (See Table 3).

\subsection{Results Chi-Square for Behavioral Biases}

The chi-square tests were conducted based on the following general hypothesis:

$\mathrm{H}_{0}$ : There is no relationship between behavioral biases \&community-based health insurance membership status; and

$\mathrm{H}_{1}$ : There is a relationship between behavioral biases \&community-based health insurance membership status.

Table 3. Descriptive statistics result among study participants' households.

\begin{tabular}{|c|c|c|c|c|c|}
\hline Variable & Label & Total N=220 (100\%) & Member N=110 (50\%) & $\begin{array}{l}\text { Not-MemberN=110 } \\
(50 \%)\end{array}$ & P-value \\
\hline \multicolumn{6}{|l|}{ Socio-demographic } \\
\hline \multirow{2}{*}{ Gender } & Female & $111(50.5)$ & $65(59.1)$ & $46(41.8)$ & \multirow{2}{*}{$0.00 * * *$} \\
\hline & Male & $109(49.5)$ & $45(40.9)$ & $64(58.2)$ & \\
\hline \multirow{4}{*}{ Marital Status } & Single & $31(14.1)$ & $6(5.5)$ & $25(22.9)$ & \multirow{4}{*}{$0.00 * * *$} \\
\hline & Married & $154(70.3)$ & $82(74.5)$ & $72(66.1)$ & \\
\hline & Separated & $17(7.8)$ & $11(10.0)$ & $6(5.5)$ & \\
\hline & Widow & $17(7.8)$ & $11(10.0)$ & $6(5.5)$ & \\
\hline $\mathrm{HH}$ age in Year & & Mean=41.4 SD=11.9 & Mean=43.1 SD=12.9 & Mean=39.6 SD $=10.7$ & \multirow{7}{*}{$0.00 * * *$} \\
\hline Year of Education & & Mean $=8.5 \mathrm{SD}=4.5$ & Mean $=7.6 \mathrm{SD}=4.5$ & Mean $=9.4 \mathrm{SD}=4.3$ & \\
\hline \multirow{5}{*}{ Employment status } & Unemployed & $19(8.7)$ & $8(7.4)$ & $11(10.1)$ & \\
\hline & Self-employed & $111(50.9)$ & $50(45.8)$ & $61(56)$ & \\
\hline & Informal-sector employee & $55(25.3)$ & $27(24.8)$ & $28(25.7)$ & \\
\hline & Homemaker & $31(14.2)$ & $23(21.1)$ & $8(7.3)$ & \\
\hline & Unable to work & $2(0.9)$ & $1(0.9)$ & $1(0.9)$ & \\
\hline \multicolumn{6}{|c|}{ Awareness on Community Health Insurance } \\
\hline \multirow{2}{*}{ Awareness on CBHI } & No & $86(39.1)$ & $41(37.2)$ & $45(40.9)$ & \multirow{2}{*}{$0.006^{* *}$} \\
\hline & Yes & $134(60.9)$ & $69(62.8)$ & $65(59.1)$ & \\
\hline \multicolumn{6}{|c|}{ Household visited the health facility in the last six month } \\
\hline Household visited the & No & $97(44.1)$ & $33(30)$ & $64(58.2)$ & \multirow[b]{2}{*}{$0.00 * * *$} \\
\hline $\begin{array}{l}\text { Health facility in the last } \\
\text { six month }\end{array}$ & Yes & $123(55.9)$ & $77(70)$ & $46(41.8)$ & \\
\hline \multicolumn{6}{|l|}{ Household characteristic } \\
\hline Household size & & Mean $=4.2 \mathrm{SD}=1.9$ & Mean $=4.4 \mathrm{SD}=1.7$ & Mean $=4.0 \mathrm{SD}=2.0$ & \\
\hline Less than age 14 & & Mean $=1.1 \mathrm{SD}=1.1$ & Mean $=1.19 \mathrm{SD}=1.0$ & Mean $=1.04 \mathrm{SD}=1.01$ & \\
\hline Between age 14 and65 & & Mean=3 SD=1.6 & Mean=3.1 SD=1.5 & Mean $=2.9 \mathrm{SD}=1.65$ & \\
\hline Greater than age 65 & & Mean $=0.2 \mathrm{SD}=0.4$ & Mean $=0.1 \mathrm{SD}=0.36$ & Mean $=0.15 S D=0.4$ & \\
\hline Dependency ratio & & Mean $=0.5 \mathrm{SD}=0.6$ & Mean $=0.53 \mathrm{SD}=0.54$ & Mean $=0.48 \mathrm{SD}=0.57$ & \\
\hline
\end{tabular}

$* * *, * *, *$ Significance at $1 \%, 5 \% \& 10 \%$, respectively.

\subsubsection{Loss Aversion Bias Test Results}

Majority of CBHI non-member households chose alternative A $(81,63.3 \%)$ from Scenario I and alternative D (93, 51.7\%) from Scenario II and test of proportions significantly different in all alternative at $1 \%$ level of significance in both scenarios (See Table 4).

\subsubsection{Status Quo Bias Test Results}

The chi-square test for scenario one and scenario two showing P-value 0.46 and 0.32 respectively. This suggests that no significant differences found in both scenarios to verify the existence of status quo bias. CBHI member and CBHI non-member households have a statistically similar pattern on status quo bias (See Table 4).

\subsubsection{Over-Optimistic Bias Test Results}

The chi-square test showed a 1 percent significance, thereby rejecting the null hypothesis. CBHI member and $\mathrm{CBHI}$ nonmember households have a statistically different pattern on overoptimistic bias test. From households who chose unlikely, 84.7\% were not members and from those households who chose likely, $66.7 \%$ were members (See Table 4 ). 


\subsubsection{Herding Bias Results}

The chi-square test for herding bias showed a P-value of 0.091 suggesting that $\mathrm{CBHI}$ member and $\mathrm{CBHI}$ non-member households have a statistically similar pattern on over herding bias test. However, most of the respondents $(81$ respondents from member and 78 respondents from nonmembers) are strongly subjected to the influence of social comparisons (See Table 4).

Table 4. Behavioral biases and CBHI membership status.

\begin{tabular}{|c|c|c|c|c|c|c|c|}
\hline \multirow{2}{*}{ Choice } & & \multicolumn{2}{|l|}{ CBHI Status } & \multicolumn{2}{|c|}{ Chi-square test } & \multicolumn{2}{|c|}{ Test of proportions } \\
\hline & & Member No. (\%) & Not-Member No. (\%) & $\operatorname{Ch2}(d f)$. & P-value & Mean Diff & P-value \\
\hline \multicolumn{8}{|c|}{ Loss-aversion bias } \\
\hline Scenario I & Alternative A & $47(36.7)$ & $81(63.3)$ & $525.02(1)$ & $0.00 * * *$ & -26.6 & $0.00 * * *$ \\
\hline \multirow{2}{*}{ Scenario II } & Alternative $\mathrm{C}$ & $22(56.4)$ & $17(43.6)$ & \multirow{2}{*}{$20.08(1)$} & \multirow{2}{*}{$0.00 * * *$} & 12.8 & $0.00 * * *$ \\
\hline & Alternative D & $87(48.3)$ & $93(51.7)$ & & & -3.3 & $0.028 * *$ \\
\hline \multicolumn{8}{|c|}{ Status-quo bias } \\
\hline Scenario I & Alternative B & $18(48.7)$ & $19(51.3)$ & 0.5391 (1) & 0.46 & -2.7 & 0.42 \\
\hline \multirow[t]{2}{*}{ Scenario II } & Alternative $\mathrm{C}$ & $97(50)$ & $97(50)$ & \multirow{2}{*}{$1.0018(1)$} & \multirow{2}{*}{0.32} & 0 & 1.00 \\
\hline & Alternative D & $12(47.8)$ & $13(52.2)$ & & & -4.3 & 0.29 \\
\hline \multicolumn{8}{|c|}{ Over-optimistic bias } \\
\hline Unlikely & & $11(15.3)$ & $61(84.7)$ & \multirow{2}{*}{$1.2(1)$} & \multirow{2}{*}{$0.00 * * *$} & -69.4 & $0.00 * * *$ \\
\hline Likely & & $98(66.7)$ & $49(33.3)$ & & & 33.4 & $0.00 * * *$ \\
\hline \multicolumn{8}{|c|}{ Herding bias } \\
\hline Disagree & & $29(48.3)$ & $31(51.7)$ & $2.849(1)$ & 0.091 & -0.4 & 0.13 \\
\hline
\end{tabular}

$* * *, * *, *$ Significance at $1 \%, 5 \% \& 10 \%$, respectively.

df- Degree of freedom.

\subsection{Results Discrete Choice Experiment}

Respondent households are less likely to select a communitybased health insurance scheme with a higher premium $(\mathrm{OR}=0.9988)$. The survey result shows private health provider $(\mathrm{OR}=9.6653)$ had the largest effect on the probability of $\mathrm{CBHI}$ alternative being chosen. If the community health insurance scheme had no exclusion from the package increased the odds of choosing a given alternative (OR=7.9983) (See Table 5).

\subsubsection{Non-Member Households}

The alternatives having no exclusion from the package increased the odds $(\mathrm{OR}=7.8814)$ of choosing a given alternative by households who are not members in the CBHI scheme. This study also found private health provider $(\mathrm{OR}=5.5337)$ had the largest effect on the probability of CBHI alternative being chosen by households who are not members in the CBHI scheme (See Table 5).

\subsubsection{Member Households}

The estimation result also confirms that the alternatives with public and private health service provider increased the odds $(\mathrm{OR}=22.1305)$ of choosing a given alternative by households who are members in the CBHI scheme. This study also found, no exclusion from the package $(\mathrm{OR}=8.6011)$ had the largest effect on the probability of CBHI alternative being chosen (see Table 5).

Table 5. Conditional LogitRegression Result.

\begin{tabular}{|c|c|c|c|}
\hline \multirow{2}{*}{ Attributes } & \multicolumn{3}{|c|}{ Odd Ratio (Standard Error) } \\
\hline & Main Sample & Not-Member & Member \\
\hline Premium & $0.9988(0001262 * * *)$ & $0.9991(0.0001713 * * *)$ & $0.9984(0.0001937 * * *)$ \\
\hline \multicolumn{4}{|l|}{ Health Service providers } \\
\hline Public & $7.6653(1.93746 * * *$ & $4.0936(1.452269 * * *)$ & $18.4579(7.074657 * * *)$ \\
\hline Private & $9.6543(2.61221 * * *)$ & $5.5337(2.074828 * * *)$ & $21.7906(9.013014 * * *)$ \\
\hline Public \& Private & $8.9481(1.96341 * * *)$ & $4.6366(1.374618 * * *)$ & $22.1305(7.762854 * * *)$ \\
\hline \multicolumn{4}{|l|}{ Benefit package } \\
\hline Exclusion of dialysis from the package & 1.00 & 1.00 & 1.00 \\
\hline Con & $0.9285(0.088018)$ & $0.91056(0.1255679)$ & $0.9297(0.1228742)$ \\
\hline Log likelihood & -890.150 & -480.95 & -395.738 \\
\hline LR chi2 (5) & 2060.45 & 954.07 & 1133.29 \\
\hline Prob $>$ chi2 & 0.000 & 0.000 & 0.000 \\
\hline Pseudo R2 & 0.5365 & 0.4980 & 0.5888 \\
\hline Wald chi2 (5) & 808.87 & 414.66 & 378.64 \\
\hline No. of observation & 5244 & 2616 & 2628 \\
\hline
\end{tabular}

$* * *, * *, *$ Significance at $1 \%, 5 \% \& 10 \%$, respectively. 


\subsection{Willingness to Pay}

As shown inTable 6, households have the highest WTP for only private health service providers, which is Birr1849.6/year compared to the neither (status quo) level. In addition, households' WTP of Birr 1787.7/year for Public \&Private health service providers and WTP of Birr 1696.1/year for No Exclusion from the package (see Table 6).

The WTP of non-member households is $41 \%$ more than
CBHI member households for no service exclusion from the package i.e. the maximum offers of non-member and member households for no service exclusion from the package are Birr2271.7/year and 1343.9/year respectively (see Table 6) compared to the neither (status quo) level. CBHI member households have the highest WTP for accessing Public \&Private service provider than their nonmember counterparts.

Table 6. Willingness to pay for main sample and CBHI membership status.

\begin{tabular}{|c|c|c|}
\hline Attributes & Coefficient $\left(-\frac{\beta_{s}}{\beta_{\text {Premium }}}\right)$ in Birr/year/person & Standard Error \\
\hline \multicolumn{3}{|l|}{ Total Sample } \\
\hline Public & 1661.433 & $181.5783 * * *$ \\
\hline Private & 1849.622 & $184.5032 * * *$ \\
\hline Public \&Private & 1787.656 & $167.0792 * * *$ \\
\hline \multirow[t]{2}{*}{ No Exclusion from the package } & 1696.121 & $153.2163 * * *$ \\
\hline & Not members & \\
\hline Public & 1550.898 & $322.7547 * * *$ \\
\hline Private & 1882.580 & $332.1287 * * *$ \\
\hline Public \&Private & 1687.955 & $286.2314 * * *$ \\
\hline \multirow[t]{2}{*}{ No Exclusion from the package } & 2271.722 & $397.9086 * * *$ \\
\hline & Members & \\
\hline Public & 1820.817 & $230.3629 * * *$ \\
\hline Private & 1924.482 & $230.2559 * * *$ \\
\hline Public \&Private & 1934.148 & $218.7792 * * *$ \\
\hline No Exclusion from the package & 1343.925 & $130.8549 * * *$ \\
\hline
\end{tabular}

$* * *, * *, *$ Significance at $1 \%, 5 \% \& 10 \%$, respectively.

\subsection{Results of the BinaryLogit Model for Determinants of CBHI Enrollment}

Table 7 shows the marginal effect estimate with standard error. This study logit result shows household head in the age group from $31-40$ are about $20 \%$ point less likely to join compared to from age group 18-30. In addition, age groups 40 to 50 and age group more than 506.6 and 7.8 percentage point less likely to join compared to from age group 18-30.

On average, female-headed households are 7.7 percentage points more likely to join the community-based health insurance scheme as compared to male-headed households. However, more years of education of the household head would decrease the probability of households to join a community-based health insurance scheme in Addis Ababa by 1.4 percentage point (see table 7).

Households who had a recent history of a visit to a health facility would have 20.1 percentage points more likely to join the community-based health insurance scheme than those who did not have. In addition, household heads who have CBHI awareness are 7.1-percentage points more likely to join a CBHI scheme as compared to household heads who did have not CBHI awareness (see table 7).

Table 7. Probability of CBHI enrolment - marginal effects.

\begin{tabular}{lcl}
\hline Variables & Marginal effects & Std. Err. \\
\hline Age groups (Base Outcome: & $18-30)$ & \\
31 to 40 & -0.2024 & $0.01897^{* * *}$ \\
41 to 50 & -0.0661 & $0.02102^{* *}$ \\
\hline
\end{tabular}

\begin{tabular}{lcl}
\hline Variables & Marginal effects & Std. Err. \\
\hline $50+$ & -0.0776 & $0.02287^{* *}$ \\
Gender & & \\
Female & 0.07697 & $0.01571^{* * *}$ \\
Marital Status (Base Outcome: Single/Unmarried) & \\
Married & 0.37613 & $0.01832^{* * *}$ \\
Separated & 0.33519 & $0.03193^{* * *}$ \\
Widow & 0.27311 & $0.03404^{* * *}$ \\
Education in year & -0.0137 & $0.00174^{* * *}$ \\
Employee Status (Base Outcome: Unemployed) & \\
Self-employed & 0.10004 & $0.02403^{* * *}$ \\
Informal Sector employee & 0.12186 & $0.02667^{* * *}$ \\
Homemaker & 0.13697 & $0.02962^{* * *}$ \\
Unable to Work & -0.1347 & $0.05313^{* *}$ \\
HH health facility visit -last six months & \\
Yes & 0.20135 & $0.01234^{* * *}$ \\
CBHI Awareness & & \\
Yes & 0.07124 & $0.01379^{* * *}$ \\
Dependency ratio & 0.03113 & $0.01289^{* *}$ \\
\hline
\end{tabular}

Log likelihood $=-2884.3961$.

LR chi2 (15) $=1014.27$.

Prob $>$ chi $2=0.0000$.

Pseudo R2 $=0.1495$.

Number of Obs. $=204$.

$* * *, * *, *$ Significance at $1 \%, 5 \% \& 10 \%$, respectively.

\subsection{Post Estimation}

Validity tests how well an instrument that is developed measures the particular concept. In this study started from a pilot test on a questionnaire, several types of validity tests generally used to test the goodness of measures. Cronbach's 
alpha used for reliability test, it used to, measure the reliability of a set of test items. One of the objectives of this study was to test behavioral biases items: loss aversion, status quo bias, over-optimistic bias, and herding bias. From the test, cronbach's alpha testfind allinternal consistency values are sufficient.

Variance Inflation Factors (VIF) were calculated multicollinearity between variables in a regression model. Which also indicate all are in an acceptable range. This study was used link test to perform model specification test by applied linktestcommand on stata. The result shows that the probability of hatsq greater than the z-value is insignificant. Therefore, the hypothesis there is a model specification problem rejected and the null hypothesis there is no model specification problem.

Hausman-McFadden test used to test for the violation of the IIA property. A Hausman- McFadden test shows that the restrictive assumption is not violated. A Hausman- McFadden test shows that the restrictive assumption IIA property is not violated. Wald test tell variables that add nothing can be deleted without affecting the model in any meaningful way, this study test wald test in stata using test command. This wald test result shows that statistical significance of each attribute. Therefore, this study concludes each attribute result in a statistically significant improvement in the fit of the model.

\section{Discussion}

The study result from loss-aversion bias test indicates thatnon- members of the CBHI are significantly subjected to loss-aversion bias. In addition, CBHI member and nonmember households have a statistically different pattern on the loss-aversion bias test. These results are consistent with the findings of Van Winssen et al. [24], which showed that the presence of loss aversion bias decreases the demand for Dutch supplementary health insurance. In addition, the results are consistent with Rice [22] which indicated the negative relationship between loss aversion bias and health insurance purchasing.

CBHI member and non-member households have a statistically different pattern on over-optimistic bias test. The results show that CBHI member households are significantly subjected to optimism bias. This study finding is consistent with Dicks [10] that indicated insurance demand is in optimism bias. In addition, the study finds no statistical difference between member and non- member households' response to herding bias. However, most of the respondents in both groups are strongly subjected to the influence of social comparisons. Therefore, herding bias substantially affect $\mathrm{s}$ the decisions of both groups of households in joining the CBHI scheme.

Different studies indicate an increase in premium is associated with a decrease in utility from health insurance [1, $2,5,12,13,21]$. The finding of this study is consistent with the aforementioned studies andin line with the principal consumer behavior, which asserts that households are less likely to select a community-based health insurance scheme with a higher premium.

Another major aim this of study to identify households' willingness to pay for different community-based health insurance attributes. By replacing the denominator of the MRS with the premium coefficient (cost coefficient), this study calculated WTP. As Ryan et al. [23] indicated when the cost is included as the denominator in trade-off calculations WTP can be estimated. The total sample result revealed that households prefer to access all health service providers, but they are more willing to pay for a private health service provider than other health service providers. In addition to this, the total sample result revealed that households are more willing to pay for health insurance schemes, which have all health service packages.

Again, the findings of the study show CBHI non-member households are more willing to pay for health insurance schemes which have all health service benefits package than other attributes justifying why non-member households do not join the scheme because the current scheme does not have health services like - dialysis and dental treatments. In addition, it found that non-member households prefer for the private health service provider than other health service providers. Furthermore, this study also shows that member households are more willing to pay for health insurance schemes which have both private $\&$ public health service provider and for only private health providers respectively.

The results of the Logit model shows that households headed by age groups of 31 to 40,41 to 50 and 50 plus have a lesser chance of joining CBHI compared to the base outcome (household heads in the age group of 18 to 30 ), which contradict with the study byAsmamaw [6]. However, the contradictions resulted due to the fact that the study areas are different (this study is based in Addis Ababa while Asmamaw's study is focused in rural Ethiopia) and probably due to the lack of age records in rural Ethiopia, which make the results of the later study doubtful. The education level of the household head has a negative and significant effect on the probability of households to enroll in CBHI against our expectations. This is because, in urban areas, the higher the education level, the greater the chances of household head joining the formal sector, which in turn reduces the probability of joining $\mathrm{CBHI}$ as formal sector employers are not eligible for CBHI scheme in Ethiopia.

On average, female-headed households have a higher chance of joiningCBHI schemes compare to male-headed households. This finding is consistent with studies $[4,6,11]$. In addition, marital and employment status distribution of household head strongly affects CBHI enrollment. For example, households who are not able to work are less likely to join to the reference unemployed household head; this is because if the households are unable to work, he/she may not be able to pay the premium.

The experience of one or more of the household members have visited a health facility in the last six month increases the probability of households joining CBHI significantly compared to those who did not. This result consistent with existing works of literature $[4,11]$ indicating that recent 
illness history increases the probability of joining the CBHI scheme. Finally, households whose heads have awareness of $\mathrm{CBHI}$ have a substantially higher chance of joining $\mathrm{CBHI}$ as compared to those who do not have such awareness. The result is in agreement with Asmamaw [6], who found that $\mathrm{CBHI}$ awareness is a significant booster of CBHI enrollment.

\section{Conclusion}

The study finding suggested behavioral biases like loss aversion bias and over-optimistic bias and herding bias significantly affect the household decisions' on communitybased health insurance enrollment. Policymakers need to recognize the impediments of behavioral biases (psychology and emotions) on CBHI enrollment as equally important as other socio-economic factors in designing health insurance schemesso thatparticipation of household in CBHI enrollment would be substantially enhanced.

The study finding reveals that respondent households are willing to pay more for comprehensive health service packages (no service exclusion from the package) and for health insurance scheme offered by private health service providers suggesting the need to design a more comprehensive community-based health insurance package and a sufficient inclusion of private actors in the health service insurance delivery.

More importantly, the results of the study inform the need to consider the launching of mandatory community-based health insurance schemes by using effective enforcement mechanisms by tailoring the schemes to different target groups with varied and flexible premiums for different social groups by taking a good consideration of how households make a decision in joining community-based health insurance schemes.

\section{References}

[1] Abiiro GA, Torbica A, Kwalamasa K, De Allegri M. Eliciting community preferences for complementary micro health insurance: A discrete choice experiment in rural Malawi. Social Science \& Medicine. 2014; 120: 160-168.

[2] Amarech O, Ryan M, Heidenreich S, Normand C, Damen H. Eliciting preferences for social health insurance in Ethiopia: a discrete choice experiment. Health Policy and Planning. 2016; 31: 423-1432.

[3] Amaya-Amaya M, Ryan M, GerardK. Using Discrete Choice Experiments to Value Health and Health Care. The Economics of Non-Market Goods and Resources. 2008; 11: 13-46.

[4] Anagaw D, Sparrow Z, Yilma GA, Bedi AS. Enrollment in Ethiopia's Community-Based Health Insurance Scheme. World Development. 2015; 74: 58-76.

[5] Anoo N. Health Insurance in Developing Countries: Willingness to Pay for Health Insurance in Thailand using Discrete Choice Experiment Methods. Curtin University: Centre for International Health; 2011.

[6] Asmamaw, A. (2018). CBHI in Ethiopia: Enrollment,
Membership renewal and Effect on health care utilization. Seoul: Seoul National University; 2018.

[7] Baicker K, William JC, Sendhil M. Health Insurance Coverage and Take-Up: Lessons from Behavioral Economics. The Milbank Quarterly. 2012; 90 (1): 107-134.

[8] Carlsson F, MartinssonP. Design Techniques for Stated Preference Methods in Health Economics. Health Econ; 2003; 12: 281-294.

[9] De AllegrM, Kouyaté B, BecherH,... Sauerborn R. Understanding enrolment in community health insurance in sub-Saharan Africa: a population based case-control study in rural Burkina Faso. Bulletin of the World Health Organization. 2006; 84: 852-858.

[10] Dicks DL, Garveny JR, Hilliardz JI. Optimism Bias and the Demand for Insurance. 2016; https://ssrn.com/abstract=1907463.

[11] Ethiopian Health Insurance Agency. Evaluation of Community-Based Health Insurance Pilot Schemes in Ethiopia: Final Report. Addis Ababa: EHIA; 2015.

[12] Kananurak P. Willingness to Pay for Voluntary Health Insurance after Retirement in Thailand. NIDA Development Journa. 2014; 54 (2): 118-157.

[13] Kamara J, Bonet MJ, Mesnard A. A Discrete Choice Experiment to Elicit the Willingness to Pay for Health Insurance by the Informal Sector Workers in Sierra Leone. International Journal of Health Economics and Policy. 2018; 3 (1): $1-12$.

[14] Kløjgaard M, Bech M, Søgaard, R. Designing a Stated Choice Experiment: The Value of aQualitative process. Journal of Choice Modeling. 2012; 5 (2): 1-18.

[15] Louviere J, LancsarE. Choice Experiments in Health: The Good, the Bad, and the Ugly and Toward a Brighter Future. Health Economics, Policy and Law. 2009; 4: 527-546.

[16] Mangham LJ, Hanson K, Mcpake B. How to Do (Or Not to Do). Designing A Discrete Choice Experiment for Application in A Low Income Country. Health Policy andPlanning. 2009; 24: $151-158$

[17] Mcfadden D (1974). Conditional Logit Analysis of Qualitative Choice Behavior. In P. Zarembka (Ed.), Frontiers in Econometrics (pp. 105-142). New York: Academic Press; 1974.

[18] MelakuH, Shimeles O, Berhane M. Willingness to join community-based health insurance among rural households of Debub Bench District, Bench Maji Zone, Southwest Ethiopia. BMC Public Health. 2014; 14: 591.

[19] Ministry of Health. HSTP 2015/16- 2019/20. Addis Ababa: Federal Ministry of Healt; 2015.

[20] Ministry of Health. Ethiopia's Sixth National Health Accounts 2013/2014. Addis Ababa: Federal Ministry of Health; 2017.

[21] Ozawa S, Grewal S, Bridges J. Household Size and the Decision to Purchase Health Insurance in Cambodia: Results of a Discrete-Choice Experiment with Scale Adjustment. Appl Health Econ Health Policy. 2016; 14: 195-204.

[22] Rice T. The Behavioral Economics of Health and Health Care. Annual Review of Public Health. 2013; 34: 431-447. 

Insights from Behavioral Economics and Discrete Choice Experiments

[23] RyanM, Amaya-AmayaM, Gerard K. Using Discrete Choice Experimentsto Value Health and Health Care. The Economics of Non-Market Goods and Resources. 2008; 11: 73-79.

[24] Van WinssenK., van KleefR, van de Ven W. The demand for health insurance and behavioral economics. Eur J Health Econ. 2016; 17: 653-657.

[25] Yamane T. Statistics: An Introductory Analysis, second Ed. New York: Harper and Row; 1967. 